\title{
HYDROXYLAMINE NITRATE AS A PLUTONIUM REDUCTANT IN THE PUREX SOLVENT EXTRACTION PROCESS
}

J. M. MCKIBBEN

J. E. BERCAW
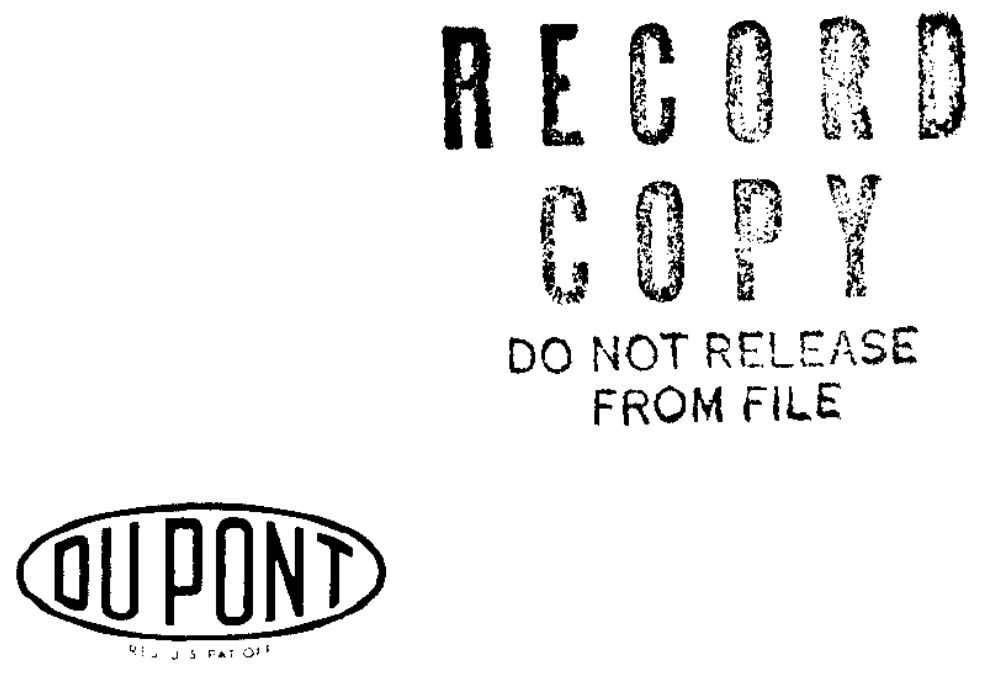

ISSUED BY

Savannah River Laboratory

Aiken, South Carolina 


\section{NOTICE}

This report was prepared as an account of work sponsored by the United States Government. Neither the United States nor the United States Atomic Energy Commission, nor any of their employees, nor any of their contractors, subcontractors, or their employees, makes any warranty, express or implied, or assumes any legal liability or responsibility for the accuracy, completeness or usefulness of any information, apparatus, product or process disclosed, or represents that its use would not infringe privately owned rights.

Printed in the United States of Americat

Available from

National Technical Information Service

U.S. Department of Commerce

Springfield, Virginia 22151

Price: Printed Copy $\$ 3.00$; Microfiche $\$ 0.65$ 
Chtnistry Verarations processe,

for Plutonium and Uranium

(T'ID-4500, Uc-10)

HYDROXYLAMINE NITRATE AS A

PLUTONIUM REDUCTANT IN THE PUREX

SOLVENT EXTRACTION PROCESS

\author{
J. Malvyn Mckibben \\ John E. Bercaw* \\ * Present address: \\ Department of Chemistry \\ University of Michigan \\ Ann Arbor, Michigan
}

Approved by

E. B. Sheldon, Superintendent

Separations Technology Section

January 1971

E. 1. DU PONT DE NEMOURS \& COMPANY

SAVANNAH RIVER LABORATORY

AIKEN, S. C. 29801

CONTRACT AT(07-2)-1 WITH THE.

UNITED STATES ATOMIC ENERGY COMMISSION 


\begin{abstract}
In laboratory tests, followed by a plant demonstration, hydroxylamine nitrate was shown to be superior to hydroxylamine sulfate for plutonium reduction in the second plutonium cycle of the Purex solvent extraction process. Hydroxylamine nitrate chemical reactions, stability, and rates of plutonium reduction were determined.
\end{abstract}




\section{CONTENTS}

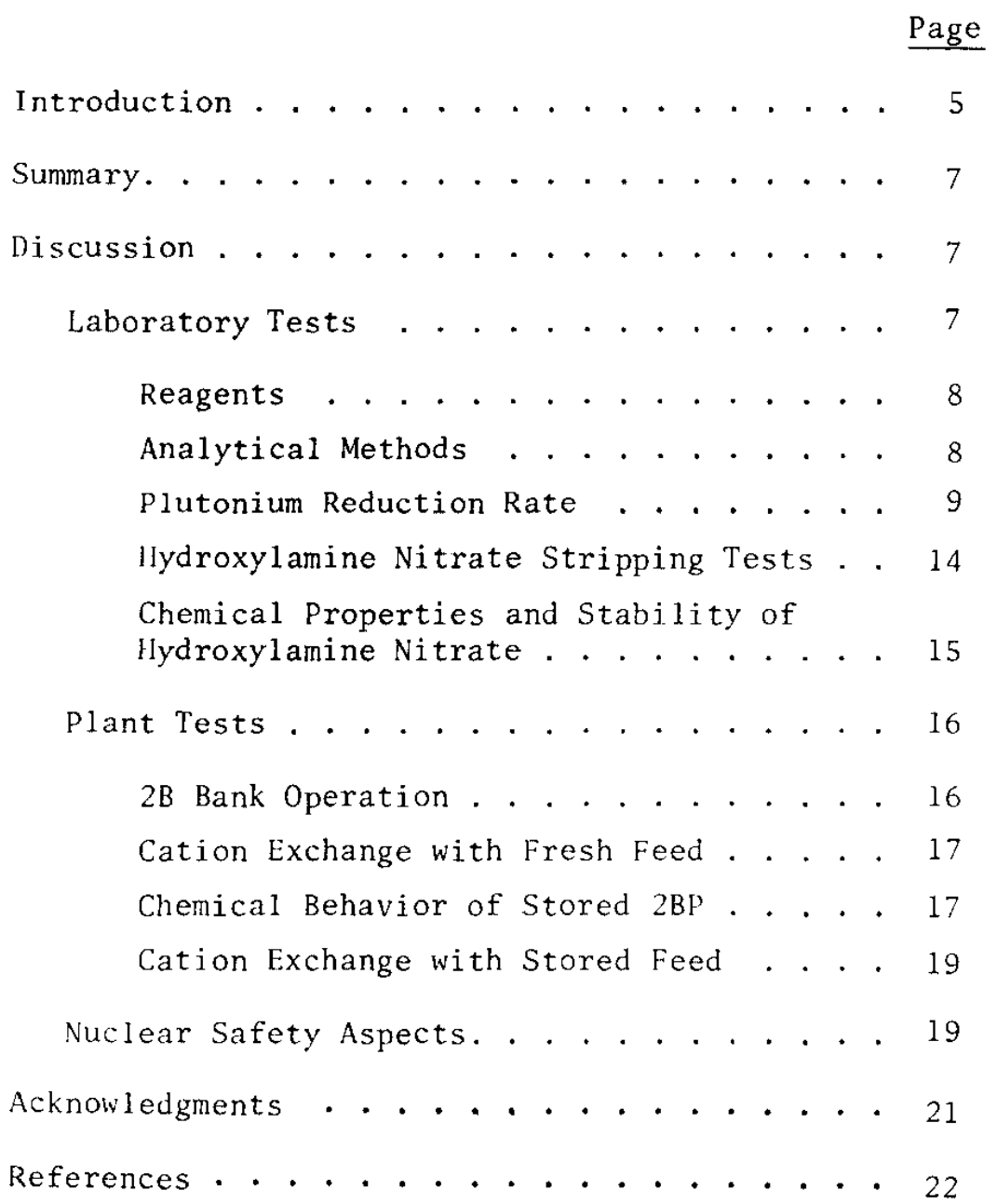




\section{LIST OF TABLES AND FIGURES}

Table

I Effect of Reductant on Molar Extinction

Coefficients . . . . . . . . . . . . . . . . . 9

II Pu(IV) Reduction with Hydroxylamine Sulfate . . . 9

III Pu(IV) Reduction with Hydroxylamine Nitrate, Hydrazine Nitrate, and Hydrazine Sulfate . . . . . 10

IV Comparison of Plutonium Reductants . . . . . . . 13

$\mathrm{V} \quad$ Comparison of Hydroxylamine Nitrate and Hydroxylamine Sulfate Stripping of Plutonium from Synthetic $2 A P$. . . . . . . . . . . . . 14

VI Comparison of Hydroxylamine Nitrate and Hydroxylamine Sulfate in Cation Exchange Stream .................

Figure

1 Purex Second Plutonium Cycle . . . . . . . . 6

2 Pu(IV) Reduction with Various Reductants...... 10

3 Effect of $\mathrm{HNO}_{3}$ on Rate of Hydroxylamine Nitrate Reduction of $\mathrm{Pu}(\mathrm{IV})$. . . . . . . . . . . . . 11

4 Effect of Iron on Rate of Pu(IV) Reduction by

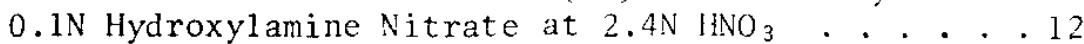

5 Hydroxylamine Nitrate Content and $\%$ Pu(III) in Stored 2BP............... . I8

6 Equilibrium Aqueous Profiles of Plutonium and $\mathrm{HNO}_{3}$. . . . . . . . . . . . . . . . . . . . . . 20 


\section{INTRODUCTION}

In large-scale processes for plutonium purification, including solvent extraction, cation exchange, and anion exchange, the plutonium usually is reduced to $\mathrm{Pu}$ (III). The principal reductants used at Savannah River Plant, and elsewhere, have been ferrous sulfamate and hydroxylamine sulfate (HAS). At some sites uranoushydrazine mixtures have been used as a substitute for ferrous sulfamate. The principal advantage of the ferrous sulfamate and uranous-hydrazine is that they give very rapid reduction of $\mathrm{Pu(IV)}$ to $\mathrm{Pu}$ (III) even in moderately strong nitric acid, and the principal advantage of HAS is that it contains no metallic cation to contaminate the product, or to consume sites on a cation exchange resin. These two reductants have several characteristics that make them less than ideal. The ferrous sulfamate is consumed in Purex first cycle greatly in excess of its stoichiometric requirements (as is uranous-hydrazine) for reasons that have not been completely explained. This excess consumption of ferrous sulfamate increases waste volume. Also, the sulfate generated by the sulfamate contributes to plutonium losses (via aqueous plutonium sulfate complexes; $j^{1,2}$ and to stainless steel corrosion. HAS reduction is slow and incomplete, and sulfate is added which is detrimental for the reasons mentioned above. There are also some disadvantages in introducing uranous ion to reduce plutonium at a step in the process where plutonium is being separated from uranium.

Interest in hydroxylamine nitrate (HAN) arose from studies of $\mathrm{Pu}(\mathrm{IV})$ reduction stripping in the Purex second cycle (Figure 1) where the Pu(IV) in $30^{\circ}$ TBP-"Ultrasene"* is stripped into a dilute nitric acid stream of HAS. The plutonium in this aqueous stream then is concentrated by a cation exchange operation that uses $\mathrm{Pu}(\mathrm{III}) .^{3}$ When using IIAS, sulfate-Pu complexes are responsible both for small routine $\mathrm{Pu}$ losses to the effluent from the cation exchange absorption column and for increased losses to the $2 \mathrm{AW}$ whenever $2 \mathrm{BP}$ is recycled to the $2 \mathrm{~A}$ bank.

Hydroxylamine nitrate appeared a likely improvement over HAS because it would not introduce the undesirable sulfate. Little information was available on its properties; therefore, laboratory and plant studies were made to determine whether HAN is a better reductant than HAS.

* Registered trademark of Atlantic-Richfield Co. 


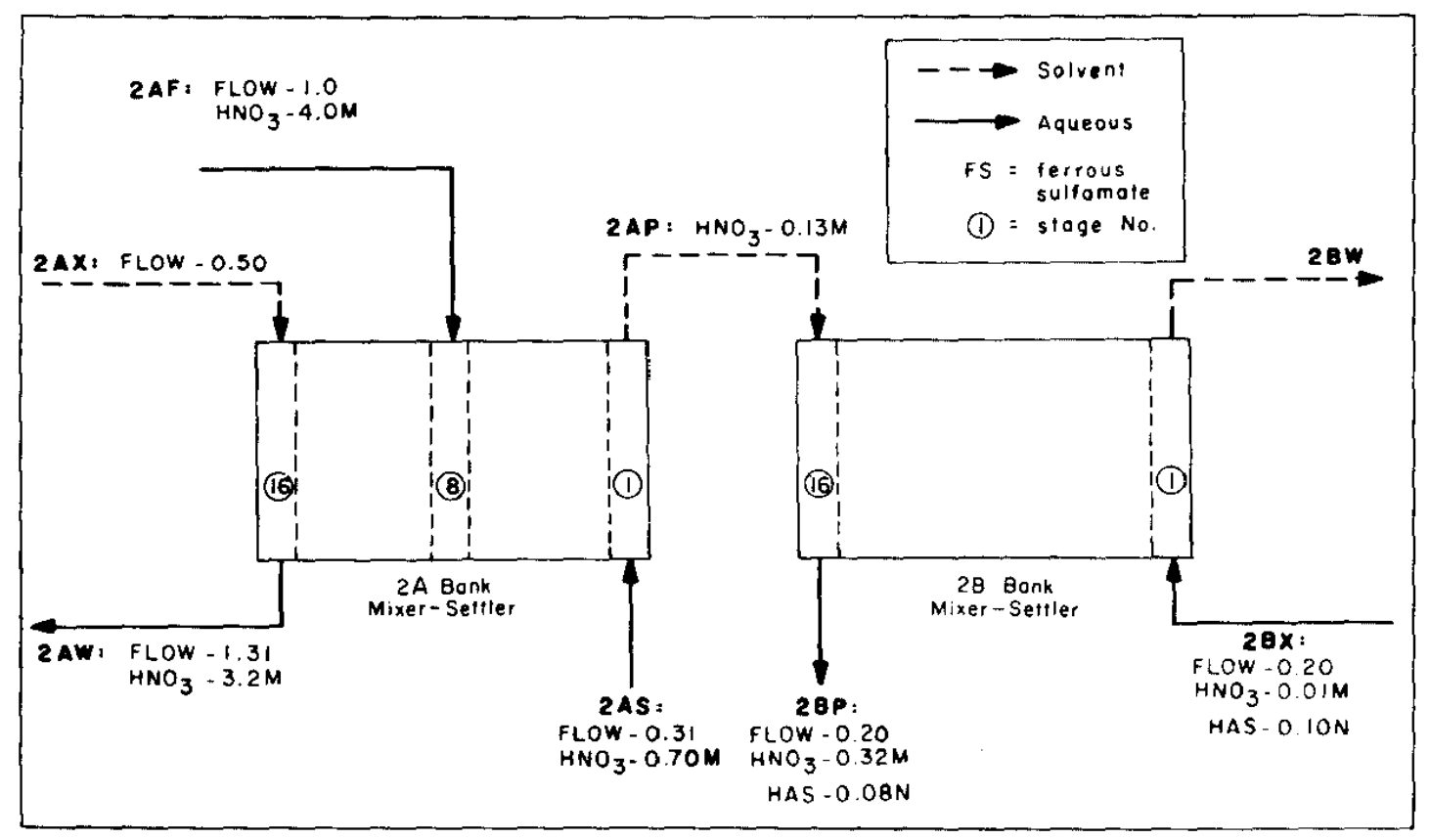

FIG. 1 PUREX SECOND PLUTONIUM CYCLE 


\section{SUMMARY}

A laboratory program, followed by a plant demonstration, established that hydroxylamine nitrate is superior to hydroxylamine sulfate as the plutonium reductant and stripping agent in the Purex second plutonium cycle. In laboratory tests $\mathrm{Pu(IV)}$ reduction rates, HAN stability, and other HAN chemical properties were measured under a variety of conditions. These data and a comparison of plant operating performances with HAN and with HAS showed that hydroxylamine nitrate offers the following advantages:

- Plutonium is rapidly and completely reduced in the second solvent extraction cycle. Consequently, losses of plutonium from the subsequent cation exchange operation are lower with IIAN by a factor of 3.5 .

- Long-term storage of the second-cycle product solution sometimes required by production schedules, is more satisfactory when HAN has been used because the aged solution can be easily readjusted to optimum column feed conditions. (When HAS has been used, storage and readjustment give high plutonium losses.)

- Sulfate is eliminated from waste and process streams, thus reducing stainless steel corrosion.

- The second-cycle product solution can be recycled through solvent extraction, if necessary, without additional plutonium losses, caused by sulfate complexing of the plutonium.

- In process waste streams HAN decomposes entirely (in boiling nitric acid) to water and gases, leaving no salt and thus reducing waste storage costs.

\section{DISCUSSION}

\section{LABORATORY TESTS}

In the laboratory tests that preceded the plant demonstration, IIAN reductions of $\mathrm{Pu}($ IV) to $\mathrm{Pu}(\mathrm{III})$ were measured under a variety of conditions, and other chemical properties of HAN were determined. 


\section{Reagents}

A portion of the hydroxylamine nitrate used in these tests was prepared in the laboratory from hydroxylamine hydrochloride by anion exchange. Later, $1.5 \mathrm{M}$ solutions of HAN were purchased from City Chemical Company, New York, and from Allied Chemical Company. The hydrazine nitrate was technical grade, obtained in solution from Savannah River Plant process chemicals stock. The hydrazine sulfate and hydroxylamine sulfate solutions were prepared from reagent-grade solid chemicals.

A stock solution of $\mathrm{Pu}$ (IV) was prepared from plutonium metal. The weighed metal was dissolved in $\mathrm{HCl}$, and the chloride was converted to nitrate by successive additions of concentrated $\mathrm{HNO}_{3}$ and evaporations on a steam bath. The final residue of $\mathrm{Pu}\left(\mathrm{NO}_{3}\right)_{4} \cdot \mathrm{xH}_{2} \mathrm{O}$ was dissolved and diluted in standardized $1.0 \mathrm{~N} \mathrm{HNO}_{3}$.

\section{Analytical Methods}

Hydroxylamine was determined by a modified version of the Rashig method." The sample aliquot was warmed with ferric ammonium sulfate in a sulfuric acid solution to reduce ferric to ferrous:

$$
2 \mathrm{NH}_{2} \mathrm{OH}+4 \mathrm{Fe}\left(\mathrm{NH}_{4}\right)\left(\mathrm{SO}_{4}\right)_{2} \rightarrow 4 \mathrm{FeSO}_{4}+2 \mathrm{H}_{2} \mathrm{SO}_{4}+\mathrm{N}_{2} \mathrm{O}+\mathrm{H}_{2} \mathrm{O}+2\left(\mathrm{NH}_{4}\right)_{2} \mathrm{SO}_{4}
$$

A small amount of sulfamic acid was added before warming to protect the ferrous from oxidation by nitrite. A few drops of phosphoric acid were added to decolorize the solution to make the end point easier to see. The ferrous was then titrated with standardized permanganate.

In spectrophotometric analyses used to determine plutonium valences, the light absorption in the solution was measured at wavelengths of maximum absorption by Pu(III) and Pu(IV). From the measured absorbances, the fractions in each valence are calculated by equations, given below, which include four molar extinction coefficients. These coefficients, $\varepsilon$, are the proportionality constants relating absorbance, $\mathrm{A}$, to concentration, $\mathrm{C}$; thus, $\mathrm{A}=\varepsilon \mathrm{C}$. (Superscripts refer to wavelength in millimicrons; subscripts refer to $\mathrm{Pu}$ valence.)

$$
R=\frac{C_{I I I}}{C_{I V}}=\frac{A^{603} \varepsilon_{I V}^{475}-A^{475} \varepsilon_{I V}^{603}}{A^{475} \varepsilon_{I I I}^{603}-A^{603} \varepsilon_{I I I}^{455}}
$$

Therefore,

$$
\because \operatorname{Pu}(\text { III })=\frac{R-100 \%}{R+1}
$$


The accuracy of such analyses depends on the accuracy of the molar extinction coefficients for the particular solution being analyzed. These coefficients were determined in simulated 2BP solutions $\left(0.3 \mathrm{~N} \mathrm{HNO}_{3}, 1.5 \mathrm{~g} \mathrm{Pu} / \ell, 0.06 \mathrm{~N} \mathrm{HAN}\right.$ or HAS) containing either HAN or HAS as reductant (Table I).

\section{Plutonium Reduction Rate}

Aliquots of the plutonium and reductant stock solutions were accurately mixed and diluted, and the $\%$ Pu(III) and Pu(IV) were determined (Tables II and III and Figure 2).

TABLE I

Effect of Reductant on Molar Extinction Coefficients

\begin{tabular}{|c|c|c|}
\hline $\begin{array}{l}\text { Reductant } \\
\text { in } 2 \mathrm{BX} \text { : }\end{array}$ & HAS & HAN \\
\hline$\varepsilon_{\text {III }}^{475}$ & 4.7 & 3.2 \\
\hline $\begin{array}{c}\varepsilon^{475} \\
I V\end{array}$ & 71.0 & 41.8 \\
\hline$\varepsilon_{\text {I I I }}^{603}$ & 31.8 & 31.8 \\
\hline$\varepsilon_{I V}^{603}$ & 5.0 & 5.0 \\
\hline
\end{tabular}

TABLE II

Pu(IV) Reduction with Hydroxylamine Sulfate $\left(0.3 \mathrm{~N} \mathrm{HNO}_{3}, 0.1 \mathrm{~N} \mathrm{HAS}, 22^{\circ} \mathrm{C}\right)$

\begin{tabular}{|c|c|c|}
\hline $\begin{array}{l}\text { Reducing } \\
\text { Time, hr }\end{array}$ & $\begin{array}{l}\circ \mathrm{Pu}(\mathrm{III}) \text { in Solution } \\
\text { Containing } 1.58 \mathrm{~g} \mathrm{Pu} / 1\end{array}$ & $\begin{array}{l}\because \text { Pu(III) in Solution } \\
\text { Containing } 3.04 \mathrm{~g} \mathrm{Pu} / 1\end{array}$ \\
\hline 1.5 & 76.2 & 74.4 \\
\hline 25.5 & 92.5 & 90.9 \\
\hline 95 & 92.8 & 90.7 \\
\hline 336 & 95.3 & 91.5 \\
\hline
\end{tabular}


TABLE II I

Pu(IV) Reduction with Hydroxylamine Nitrate, Hydrazine Nitrate, and Hydrazine Sulfate

$\left(1.5 \mathrm{~g} \mathrm{Pu} / 1,0.3 \mathrm{~N} \mathrm{HNO}_{3}, 22^{\circ} \mathrm{C}\right)$

\begin{tabular}{|c|c|c|c|}
\hline Reduct ant & Concentration & Reducing Time & $\because \mathrm{Pu}(\mathrm{III})$ \\
\hline \multirow[t]{2}{*}{$\mathrm{NH}_{2} \mathrm{OH} \cdot \mathrm{HNO}_{3}$} & $0.0205 \mathrm{~N}$ & $\begin{array}{l}1.5 \mathrm{hr} \\
4.0\end{array}$ & $\begin{array}{r}99.7 \\
100.0\end{array}$ \\
\hline & $0.0435 \mathrm{~N}$ & $\begin{array}{l}0.5 \mathrm{hr} \\
150 \\
4 \text { weeks }\end{array}$ & $\begin{array}{c}100.0 \\
99.5 \\
\text { Still clcar bluc: }\end{array}$ \\
\hline $\mathrm{N}_{2} \mathrm{H}_{4} \cdot \mathrm{HNO}_{3}$ & $0.04 x$ & $\begin{array}{l}0.5 \mathrm{hr} \\
1.0 \\
2.5 \\
18.5 \\
48\end{array}$ & $\begin{array}{l}10.0 \\
12.7 \\
38.7 \\
86.5 \\
99.2\end{array}$ \\
\hline$\left(\mathrm{N}_{2} \mathrm{H}_{4}\right)_{2} \cdot \mathrm{H}_{2} \mathrm{SO}_{4}$ & $0.04 X$ & $2.0 \mathrm{hr}$ & $\begin{array}{r}51 \\
80\end{array}$ \\
\hline
\end{tabular}

a. Pu(III) is blue; Pu(IV) is brom.

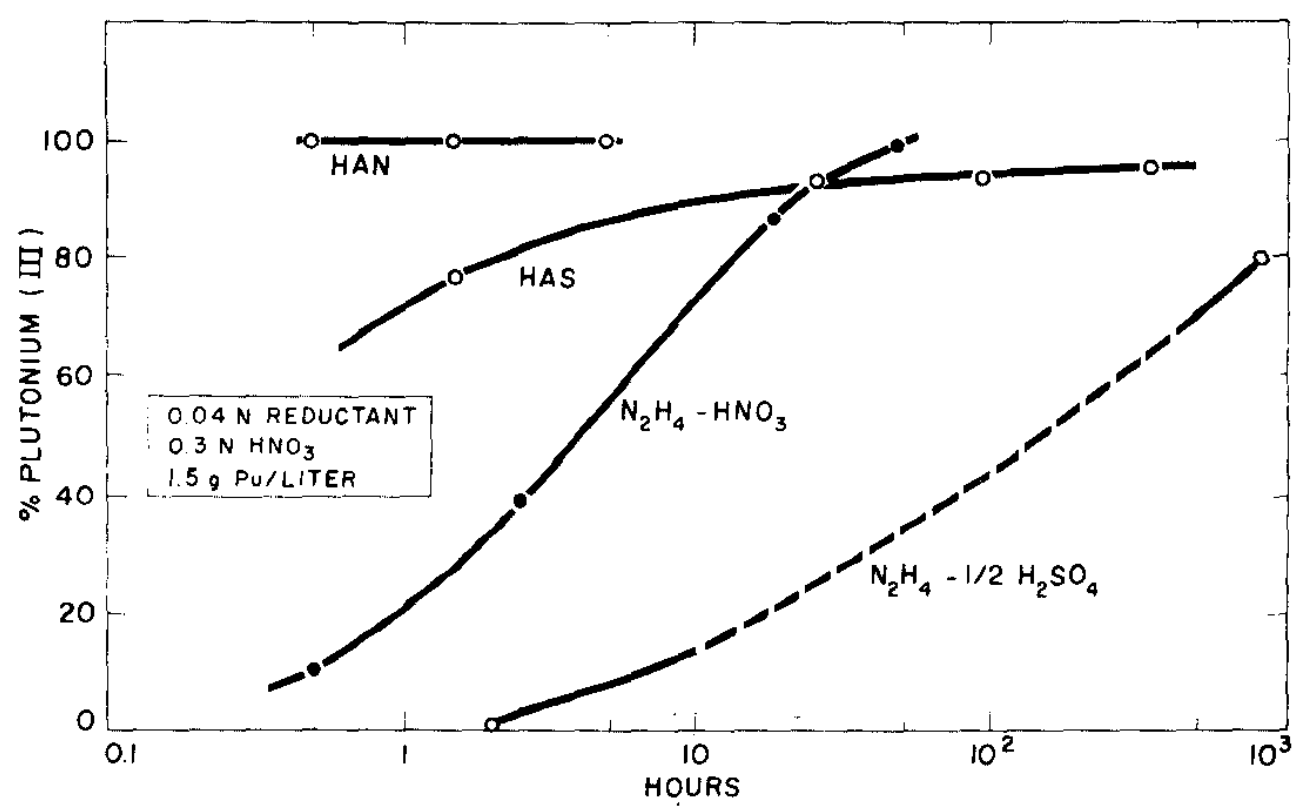

FIG. 2 PU(IV) REDUCTION WITH VARIOUS REDUCTANTS 
These tests confirmed that the sulfate ion is responsible for the slow and incomplete reduction of plutonium in the 2BP because in all cases (hydroxylamine and hydrazine) the presence of the sulfate retarded reduction. The hydroxylamine nitrate gave rapid and complete reductions. The hydrazine nitrate gave complete, but slower, reduction than HAN. The slower reduction rate of the hydrazine nitrate would not be significant if it were used as the $2 \mathrm{BX}$, because adequate time delay exists for complete reduction before the ion exchange operation. The sulfate form of hydrazine was extremely slow in reducing $\mathrm{Pu}(\mathrm{IV})$.

The reduction rate of plutonium by $\mathrm{HAN}$ was measured at $0.30 \mathrm{~N}$, $0.94 \mathrm{~N}$, and $2.39 \mathrm{~N} \mathrm{HNO}_{3}$. The results (Figure 3) reveal a sharp decrease in reduction rate with increasing acidities. However, at the low acidity found in the $2 \mathrm{~B}$ bank and cation exchange column feed $(20.3 N)$ the reduction is very rapid.

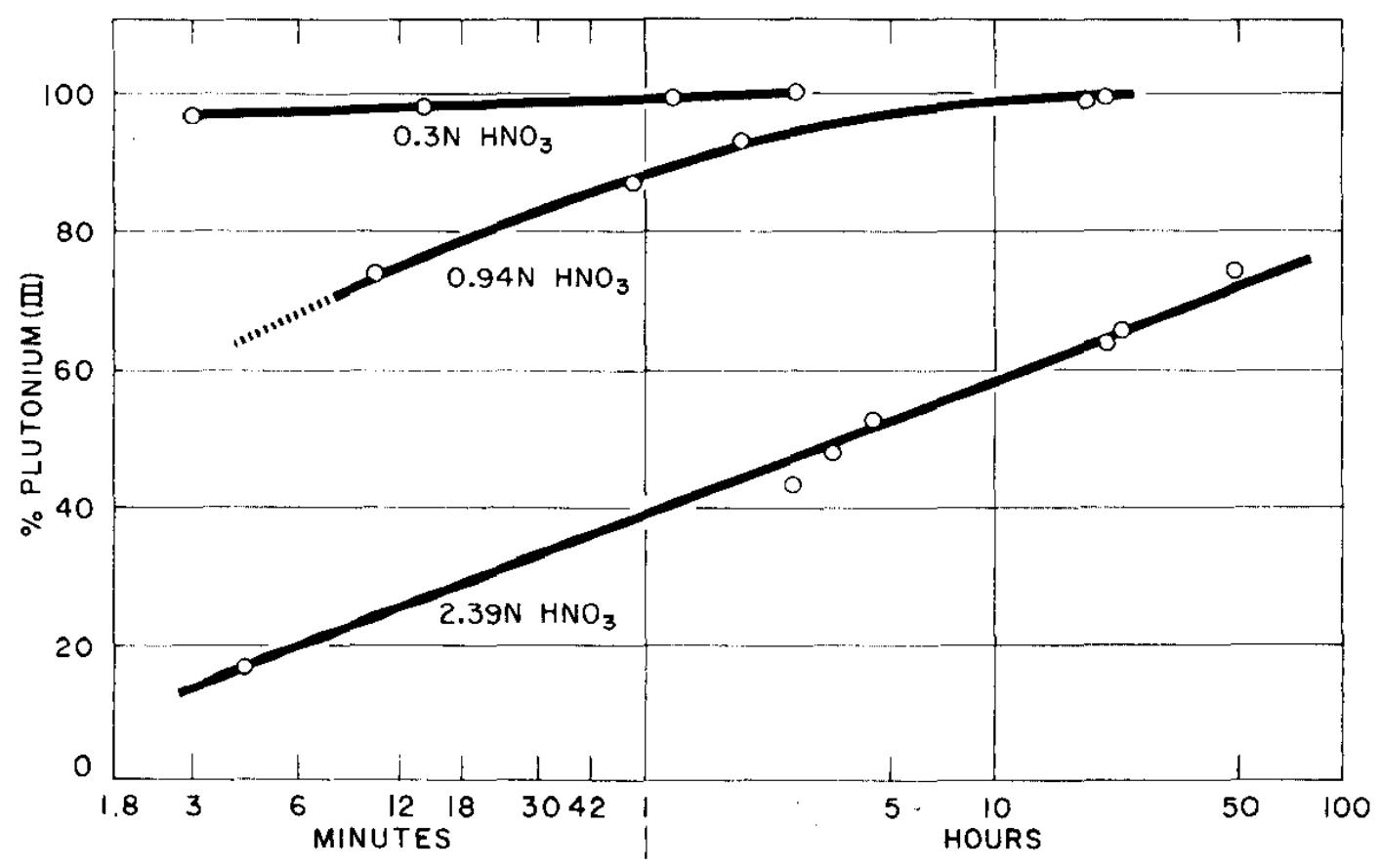

FIG. 3 EFFECT OF $\mathrm{HNO}_{3}$ ON RATE OF HYDROXYLAMINE NITRATE REDUCTION OF PU(IV) 
At higher acidities, ferric ion catalyzes the reduction as follows:

$$
\begin{aligned}
& 2 \mathrm{NH}_{2} \mathrm{OH}+4 \mathrm{Fe}^{3+} \longrightarrow 4 \mathrm{Fe}^{2+}+\mathrm{N}_{2} \mathrm{O}+\mathrm{H}_{2} \mathrm{O}+4 \mathrm{H}^{+} \\
& \frac{4 \mathrm{Fe}^{2+}+4 \mathrm{Pu}^{4+} \longrightarrow 4 \mathrm{Pu}^{3+}+4 \mathrm{Fe}^{3+}}{2 \mathrm{NH}_{2} \mathrm{OH}+4 \mathrm{Pu}^{4+} \longrightarrow 4 \mathrm{Pu}^{4+}+\mathrm{N}_{2} \mathrm{O}+\mathrm{H}_{2} \mathrm{O}+4 \mathrm{H}^{+}}
\end{aligned}
$$

This catalysis by iron extends the utility of HAN reductions into higher acidities. For example, Figure 4 shows the increased plutonium reduction rate caused by $0.1 \mathrm{M}$ iron, added as $\mathrm{Fe}^{3+}$, at $2.4 \mathrm{~N} \mathrm{HNO}_{3}$. In addition, tests showed that ferrous-HAN solution was as effective as ferrous sulfamate in preventing re-oxidation of $\mathrm{Pu}$ (III) in this nitric acid solution and that a ferroushydrazine mixture was unstable at this acidity (Table IV). These data suggest that a mixture of ferrous nitrate-hydroxylamine nitrate might be used, rather than ferrous sulfamate, as the plutonium partitioning agent in the Purex first cycle where the acidity is higher than in the second cycle.

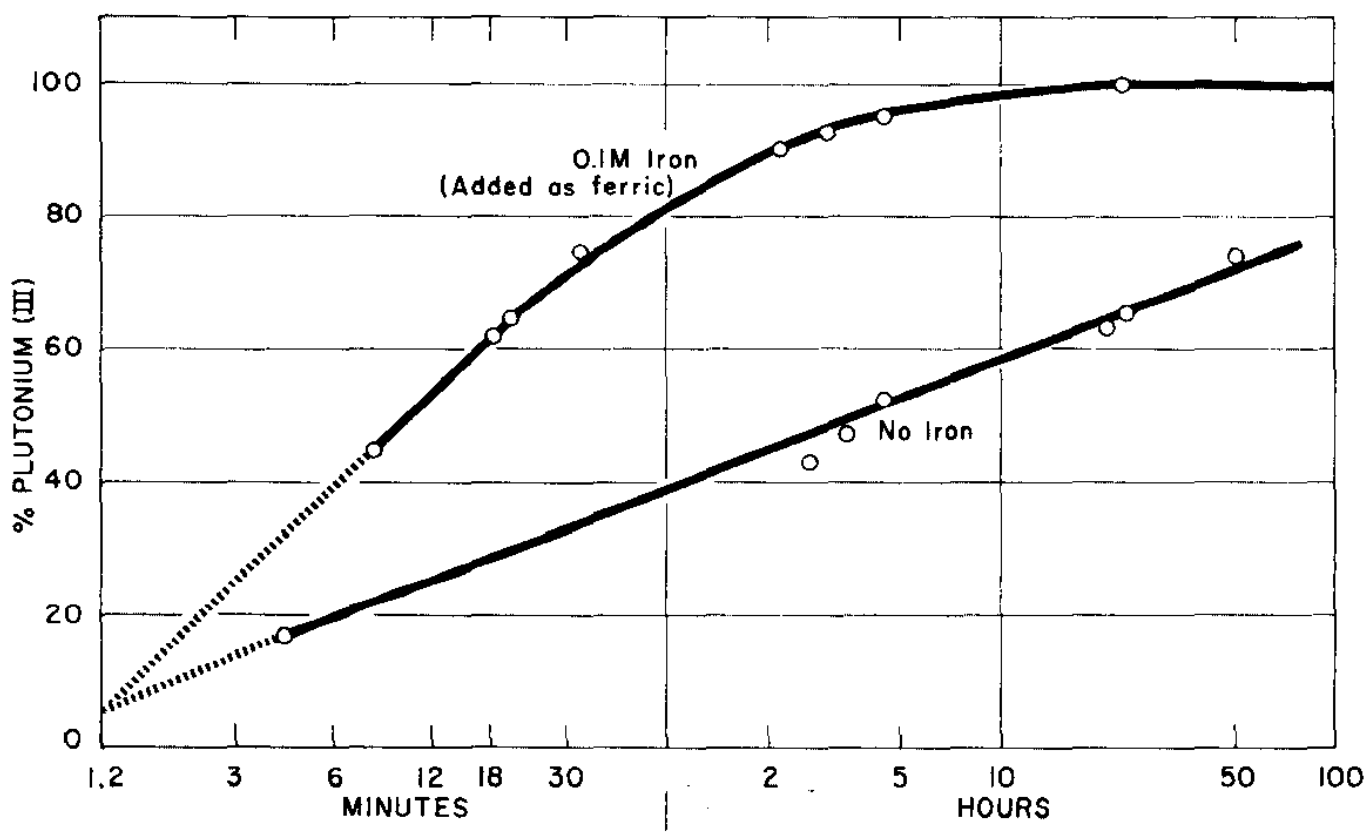

FIG. 4 EFFECT OF IRON ON RATE OF PU(IV) REDUCTION BY $0.1 \mathrm{~N} \mathrm{HYDROXYLAMINE}$ NITRATE AT $2.4 \mathrm{~N} \mathrm{HNO}_{3}$ 
TABLE IV

Comparison of Plutonium Reductants

$\left(2.0 \mathrm{~g} \mathrm{Pu} / 1 ; 2.5 \mathrm{~N} \mathrm{HNO}_{3}\right)$

\begin{tabular}{|c|c|c|c|c|c|c|c|c|}
\hline \multirow[b]{2}{*}{ Reductant } & \multirow[b]{2}{*}{ Constituent } & \multicolumn{7}{|c|}{ Concentrations after $x$ days } \\
\hline & & Initial & 1 & 2 & 5 & 7 & 19 & 28 \\
\hline \multirow[t]{3}{*}{ Ferrous sulfamate } & Ferrous, $\mathrm{N}$ & 0.102 & 0.092 & 0.086 & 0.079 & 0.076 & 0.052 & 0.041 \\
\hline & Sulfamate, $\mathrm{N}$ & 0.72 & 0.71 & - & 0.66 & 0.67 & 0.65 & 0.527 \\
\hline & ${ }_{0}^{\circ} \mathrm{Pu}(\mathrm{III})^{a}$ & $100 \%$ & $100 \%$ & $100 \%$ & $100 \%$ & $100 \%$ & $100 \%$ & $100 \%$ \\
\hline \multirow{2}{*}{$\begin{array}{l}\text { Hydroxylamine nitrate- } \\
\text { ferrous nitrate }\end{array}$} & $\mathrm{RN}^{b}$ & 0.152 & 0.120 & 0.121 & 0.108 & 0.102 & 0.068 & 0.050 \\
\hline & $\because \operatorname{Pu}(I I I)$ & $100 \%$ & $100 \%$ & $100 \%$ & $100 \%$ & $100 \%$ & $100 \%$ & $100 \%$ \\
\hline \multirow{3}{*}{$\begin{array}{l}\text { Hydrazine nitrate- } \\
\text { ferrous nitrate }\end{array}$} & Ferrous, $\mathrm{N}$ & $0.1^{c}$ & 0 & 0 & 0 & 0 & 0 & 0 \\
\hline & Hydrazine, $\mathrm{N}$ & 0.1 & 0 & 0 & 0 & 0 & 0 & 0 \\
\hline & $\% \mathrm{Pu}(\mathrm{III})$ & $100 \%$ & 0 & 0 & 0 & 0 & 0 & 0 \\
\hline
\end{tabular}

a. Estimation based on observation of color: Pu(III) is blue; Pu(IV) is brown.

i. Total reducing normality, $R N$, ferrous plus hydroxylamine. The ferrous normality was 0.08 initially based on stock solution analysis.

c. Values for ferrous and hydrazine normality are calculated from strengths of stork solutions used to prepare the mixture. Upon mixing, the Pu(IV) was reduced immediately, but within 30 seconds returned to the brown Pu(IV). Analyses several hours later showed that no ferrous or hydrazine remained in the solution. 


\section{Hydroxylamine Nitrate Stripping Tests}

In the $2 \mathrm{~B}$ bank, $\mathrm{Pu}(\mathrm{IV})$ is stripped from the organic phase with $0.10 \mathrm{~N} \mathrm{HAS} \mathrm{in} 0.01 \mathrm{M} \mathrm{HNO}_{3}$ (Figure 1). When using HAS, which reduces plutonium quite slowly, the stripping comes primarily by the preference of the $\mathrm{Pu}(\mathrm{IV})$ for the dilute nitric acid. The sulfate aids by complexing the Pu(IV) in the aqueous phase.

In tests simulating stripping in the $2 \mathrm{~B}$ bank, the stripping rates of HAN and HAS were compared. Separate aliquots of a synthetic $2 A P$ were contacted three times with fresh quantities of strip solutions of either $\mathrm{HAN}$ or HAS in $0.01 \mathrm{~N} \mathrm{HNO}_{3}$ (Table V).

Although HAS strip solutions did extract the plutonium from the organic phase more completely in the first contact, HAN extracted almost all of the plutonium (99.98\%) after three contacts. The faster HAN reduction of Pu(IV) to the less extractable Pu(III) somewhat compensated for the absence of sulfate, which aids in the HAS stripping by forming an aqueous-soluble complex with $\mathrm{Pu}(\mathrm{IV})$.

TABLE $V$

Comparison of Hydroxylamine Nitrate and Hydroxylamine Sulfate Stripping of Plutonium from Synthetic 2AP

\begin{tabular}{|c|c|c|c|c|}
\hline Test & $\begin{array}{l}\text { Contact } \\
\text { Time } \\
\end{array}$ & $\begin{array}{c}\text { Strip } \\
\text { Solution } \\
\end{array}$ & $\begin{array}{l}\text { Contact } \\
\text { Number }\end{array}$ & $\begin{array}{l}\text { \%u Remaining } \\
\text { in Solvent }\end{array}$ \\
\hline \multirow[t]{6}{*}{1} & $50 \mathrm{sec}$ & $0.05 \mathrm{~N}$ HAS & 1 & 6.1 \\
\hline & & & 2 & 0.029 \\
\hline & & & 3 & 0.007 \\
\hline & & $0.05 \mathrm{~N}$ HAN & 1 & 18.3 \\
\hline & & & 2 & 0.076 \\
\hline & & & 3 & 0.025 \\
\hline \multirow[t]{2}{*}{2} & $5 \mathrm{~min}$ & $0.05 \vee$ IIAS & 1 & 3.5 \\
\hline & & $0.05 \mathrm{~N}$ HAN & 1 & 5.4 \\
\hline
\end{tabular}

a. All strip solutions were $0.01 \mathrm{~N} 1 \mathrm{N \textrm {NO } _ { 3 }}$. 
Chemical Properties and Stability of Hydroxylamine Nitrate

Aqueous solutions of HAN are quite stable, even at temperatures up to $100^{\circ} \mathrm{C}$. Solutions have been stored in the laboratory in polyethylene and glass bottles for nearly three years with no decomposition. On several occasions 1.6M HAN solutions have been concentrated by heating, sometimes boiling vigorously, with no loss of HAN. An $8 \mathrm{M}$ HAN solution prepared in this manner was stored without any decomposition for approximately one year.

Dilute nitric acid solutions of HAN are also stable at room temperatures. For example, a $0.2 \mathrm{~N} \mathrm{HAN}-0.1 \mathrm{~N} \mathrm{HNO}_{3}$ solution in the laboratory has not shown any decomposition in over two years of storage. However, in stronger nitric acid the HAN demonstrates increasing instability, especially at elevated temperatures. For example, boiling a $0.8 \mathrm{M} \mathrm{IIAN} \mathrm{-} 1.0 \mathrm{M} \mathrm{HNO}_{3}$ solution for approximately one-half hour destroyed all the HAN, but at room temperature the same solution lost little, if any, HAN in several days. When decomposition of HAN in warm nitric acid is initiated, it proceeds autocatalytically, with $\mathrm{N}_{2} \mathrm{O}$ as the nearly exclusive reaction product based on a single mass spectrometer analysis of collected off-gas. Presumably, then, this reaction is

$$
4 \mathrm{~N} ! \mathrm{H}_{2} \mathrm{O} \mathrm{I}+2 \mathrm{HNO}_{3} \rightarrow 3 \mathrm{~N}_{2} \mathrm{O}+7 \mathrm{H}_{2} \mathrm{O}
$$

Caustic solutions of HAN are less stable than the acid solutions, decomposing by the reaction ${ }^{5}$

$$
4 \mathrm{H}_{2} \mathrm{NOH} \cdot 1 \mathrm{NOO}_{3}+4 \mathrm{OH}^{-} \longrightarrow \mathrm{N}_{2} \mathrm{O}+2 \mathrm{NH}_{3}+4 \mathrm{NO}_{3}^{-}\left(\Delta \mathrm{F}^{\circ}=-119 \mathrm{kcal}\right)
$$

However, very dilute caustic solutions are moderately stable, as indicated by a $0.2 \mathrm{M}$ HAN $-0.1 \mathrm{~N} \mathrm{NaOH}$ solution which lost about $10 \%$ of its strength in 26 days. When the solution was analyzed 12 months later, it contained no HAN. In a separate test, an attempt to distill $\mathrm{NH}_{2} \mathrm{OH}$ was made after adjusting a $1.6 \mathrm{M}$ HAN solution to a pll of 11 with NaOH. The condenser outlet was submerged under $3 \mathrm{~N} \mathrm{INO}_{3}$ to trap any $\mathrm{NH}_{2} \mathrm{OH}$ that distilled; however, no $\mathrm{NH}_{2} \mathrm{OH}$ distilled, and none survived the gentle boiling in the distillation flask. There was a strong smell of ammonia when the flask was opened. 
HAN is extremely hygroscopic. It was reported ${ }^{6}$ that the solid HAN could not be produced even with phosphorus pentoxide desiccant at $20 \mathrm{~mm}$ pressure. However, another investigation reported that a white gumny mass of $\mathrm{NH}_{2} \mathrm{OH} \cdot \mathrm{HNO}_{3}$ was produced by evaporating at $-10^{\circ} \mathrm{C}$. The salt was reported ${ }^{6}$ to "me $1 t^{\prime \prime}$ at $48^{\circ} \mathrm{C}$ and decompose at $100^{\circ} \mathrm{C}$, leaving no residue:

$\mathrm{NH}_{2} \mathrm{OH} \cdot \mathrm{HNO}_{3} \rightarrow \mathrm{N}_{2}+\mathrm{O}_{2}+2 \mathrm{H}_{2} \mathrm{O}(\Delta \mathrm{F}=-50.3 \mathrm{kcal})$

In laboratory tests, $1.00 \mathrm{ml}(1.270 \mathrm{~g})$ of $8.0 \mathrm{M}$ HAN solution in an open beaker in the direct draft of a laboratory hood at $45 \%$ humidity reached steady state at approximately $11 \mathrm{M}$ and remained clear and colorless. Because the solution was hygroscopic, it would not crystallize.

One test showed that solutions of HAN, if placed in intense heat such as might occur in a warehouse fire, will not decompose explosively if they are not confined. Twenty milliliters of 8M IIAN were placed in a small distillation flask and heated with the direct, full open flame of a laboratory propane burner. Rapid distillation of the water began until half of the volume remained, at which time foaming began, nearly filling the round part of the flask with foam. Within 15 seconds after the foaming began, all reaction had ended, and the flask was completely empty. No residue could be seen. The evolved gases were mainly colorless; however, near the end of the reaction some red-brown color, presumably of $\mathrm{NO}_{2}$, was seen.

\section{PLANT TESTS}

Full-scale plant tests were conducted in 1968 using IIAN in the process $2 \mathrm{BX}$ stream. A portion of this product solution, containing several $\mathrm{kg} \mathrm{Pu}$, was stored until the ILAN had all decomposed, at about 95 days, at which time the $\%$ Pu(III) dropped from $100 \%$ to $0 \%$. It was then readjusted and processed through cation exchange.

\section{B Bank Operation}

The $2 B$ bank operation was unaffected by substituting HAN for HAS in the 2BX. All set points, acidities, flows, and concentrations were unchanged from normal operation with lIAS, and the neutron monitors showed little, if any, increase in plutonium inventury in the bank, indicating, as laboratory test.s had predicted, that the much more rapid reduction of $\mathrm{Pu}($ IV) to the less extractable Pu(III) by HAN offset the stripping effect of the sulfate in llAS. Analyses of the plutonium valence in fresh $2 \mathrm{BP}$ showed $>98 \% \mathrm{Pu}$ (III). With HAS, the plutonium is $90-95 \% \mathrm{Pu}$ (III). 


\section{Cation Exchange with Fresh Feed}

When fresh $2 \mathrm{BP}$ was subsequently processed through cation exchange, the normal loading losses were reduced by a factor of 3.5 as shown in Table VI. This imporvement was anticipated, because most of the routine losses are caused by Pu-sulfate complexes which are unabsorbed on the resin. Also, the absence of $\mathrm{Pu}(\mathrm{IV})$ and its sulfate complexes give a sharper loading band, or less "tail," on the column, after several loading-elution cycles.

\section{TABLE VI}

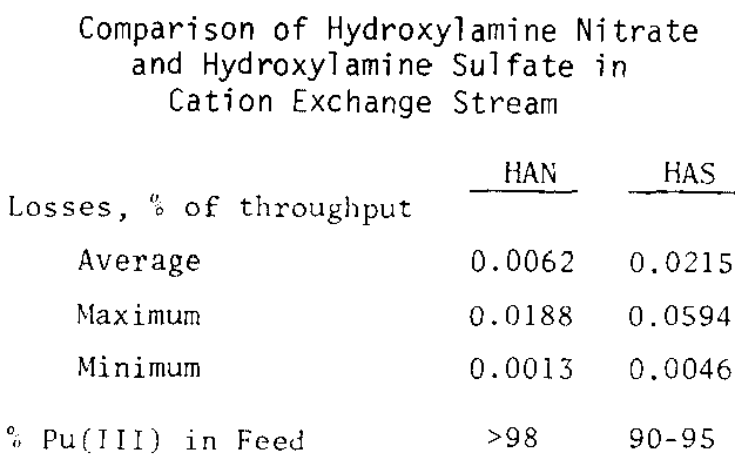

\section{Chemical Behavior of Stored 2BP}

A portion of the $2 \mathrm{BP}$, containing several $\mathrm{kg}$ of $\mathrm{Pu}$ that was produced with HAN, was stored for approximately 100 days before it was readjusted and processed through cation exchange. During the storage there was sufficient evaporation from the vented tank to concentrate the plutonium and acid by a factor of 1.7. The plutonium valence and decomposition of HAN during the storage are shown in Figure 5 . The plutonium remained at about $100 \%$ Pu(III) until the HAN began to decompose rapidly after 90 days of storage. This is distinctly different from the behavior of HAS, where the $\%$ Pu(III) decreases with decreasing HAS concentration (or increasing ratio of sulfate to hydroxylamine ion). The decomposition of HAN followed firstorder mathematics for about 90 days, i.e., the rate of decomposition was proportional to the quantity present and, therefore, was independent of plutonium concentration, acidity, and changes in its own concentration. This behavior was confirmed by samples of the same $2 \mathrm{BP}$ retained in the laboratory at constant volume, part in 
laboratory light and part in total darkness, which decomposed identically to that stored in the plant. After approximately 90 days, when the HAN concentration had decreased to approximately $0.025 \mathrm{~N}$, the decomposition became rapid, and $\mathrm{Pu}(\mathrm{IV})$ appeared in the solution for the first time. The laboratory sample was subsequently readjusted to $0.025 \mathrm{~N}$, and it continued at $100 \% \mathrm{Pu}(\mathrm{III})$ for several more months, indicating that the initiation of rapid decomposition is not a simple function of the HAN concentration.
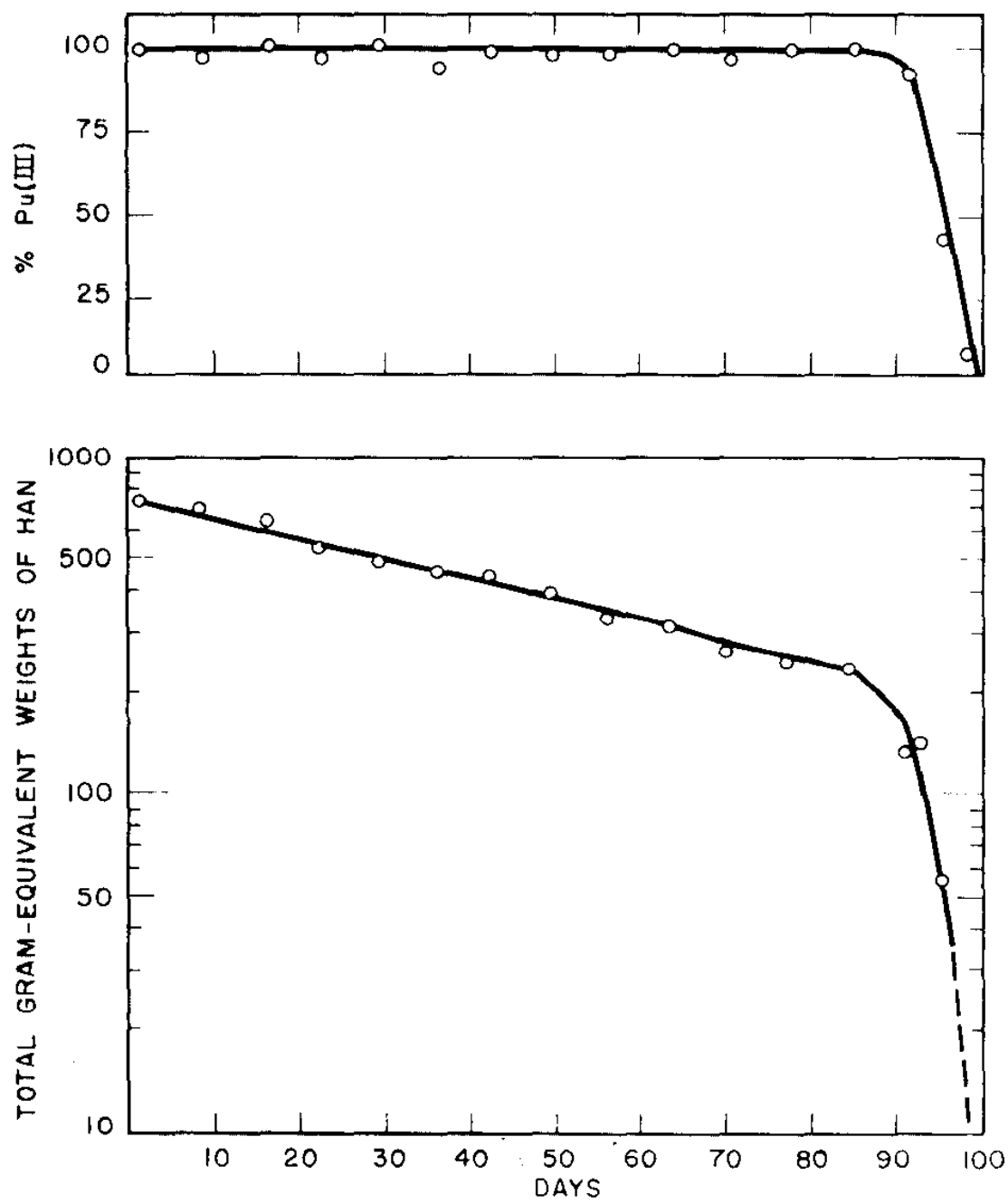

FIG. 5 HYDROXYLAMINE NITRATE CONTENT AND \% PU(III) IN STORED 2BP 


\section{Cation Exchange with Stored Feed}

The stored $2 \mathrm{BP}$ was diluted to its original volume and then readjusted in two separate batches to $0.18 \mathrm{~N}$ and $0.063 \mathrm{~N}$ HAN.

The plutonium in the two batches was analyzed as $96 \%$ and $99 \%$ Pu(III). Both batches were processed satisfactorily, although some gassing on the column occurred with the lower reducing normality; this also occurs with HAS at such a low concentration of reductant. Column losses were 0.004 to $0.04 \%$. Previous experience in processing stored 2BP when HAS was used gave losses between 0.1 and 1.0 at about $80 \%$ Pu(III), unless process conditions were changed.

Some of the stored 2BP had fine solids which caused some pluggage of a filter ahead of the cation exchange column. Analyses indicated these were probably inorganic phosphates, but they contained no plutonium. Previous solids associated with stored 2BP (with HAS) contained plutonium and some organic phosphates, and was believed to be a mixture of plutonium monobutylphosphate and plutonium dibutylphosphate. It is assumed that the phosphate comes from degradation of entrained and dissolved TBP in the 2BP. The absence of plutonium in solids in the HAN case is probably attributable to the fact that the plutonium remained as Pu(III), which has less tendency to form insoluble phosphates, mono- and di-butyl phosphates, than Pu(IV). By the time the Pu(IV) appeared, perhaps all available phosphate had precipitated.

\section{NUCLEAR SAFETY ASPECTS}

Buildup of a critical mass of plutonium in the $2 \mathrm{~B}$ bank is certainly unlikely under normal operation, but one occurrence should be guarded against when making changes in process variables. When excess sodium nitrite is added to adjust $2 \mathrm{AF}$, sufficient nitrous acid can be extracted into the $2 \mathrm{AP}$ to destroy all the hydroxylamine and to keep all of the plutonium in the $2 \mathrm{~B}$ bank in the Pu(IV) valence. This occurrence will cause an increase in the plutonium inventory in the $2 \mathrm{~B}$ bank because of the much higher distribution coefficient* of Pu(IV).

At the Savannah River Plant, operating limits on flow ratios and stream acidities are set to preclude accumulation of a critical mass even if this should happen. Backup protection is provided by in-line measurement of the conductivity (hence, acidity) of the $2 \mathrm{BP}, 2 \mathrm{AS}$, and $2 \mathrm{BX}$ streams, and by a neutron monitor over stages 12-14 of the $2 \mathrm{~B}$ mixer-settler.

* Distribution coefficient $=\frac{[\mathrm{Pu}]_{\text {solvent }}}{[\mathrm{Pu}]_{\text {aqueous }}}$. 
Previous evaluations of the nuclear safety in the Savannah River Plant's $2 \mathrm{~B}$ bank have taken into account the complexing strength of sulfate (from HAS) to strip Pu(IV) from the solvent in the $2 \mathrm{~B}$ bank in the hypothetical excess nitrite occurrences. With HAN, which has no sulfate, the only stripping action in such a situation would come from the normal distribution of Pu(IV) between the phases. Therefore, to allow use of HAN, a reexamination of nuclear safety in the $2 \mathrm{~B}$ bank under such unusual conditions was conducted. Computer calculations were made of $\mathrm{Pu}$ and $\mathrm{HNO}_{3}$ profiles in the $2 \mathrm{~B}$ bank for the simulated nitrite incident at a variety of conditions, including the most unfavorable acid and flow conditions allowed by operating limits. Distribution coefficients, $\mathrm{D}_{\mathrm{a}}^{\circ}$, for $\mathrm{Pu}(\mathrm{IV})$ and Pu(III) were taken from Reference 7. Values for $\mathrm{HNO}_{3} \mathrm{D}$ O were from Reference 8 . Calculations were made with a slightly modified version of the computer code described by Lowe. ${ }^{9}$

Concentration profiles are shown in Figure 6. Under the most unfavorable conditions, a stable profile is reached with maximum plutonium concentration of $8.52 \mathrm{~g} / 1$ and a bank inventory that is safe in Savannah River's mixer-settlers. If the nitrite incident did occur, the $2 B$ bank neutron monitor would alarm before the maximum concentration was reached, as an additional safety feature.

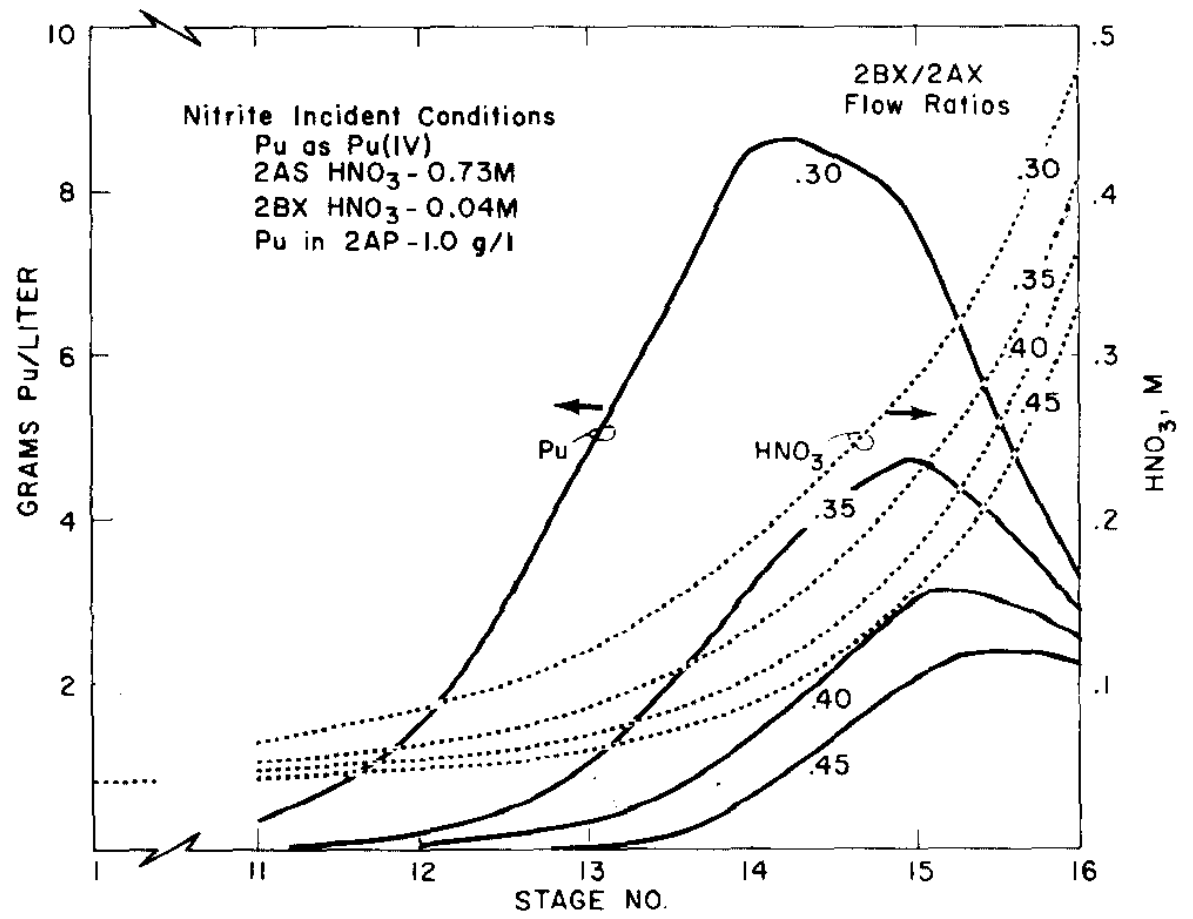

FIG. 6 EQUILIBRIUM AQUEOUS PROFILES OF PLUTONIUM AND $\mathrm{HNO}_{3}$ 


\section{ACKNOWLEDGMENTS}

The authors gratefully acknowledge the assistance of W. C. Scotten who made the computer calculations for nuclear safety analyses, and Mary S. Dodgen and M. L. Latimer who carried the responsibility for the plant tests. The valuable advice and consultation of D. A. Orth is also gratefully acknow ledged. 


\section{REFERENCES}

1. J. C. Hindman. "Ionic and Molecular Species of Plutonium in Solution." The Actinide Elements. G. T. Seaborg and J. J. Katz (ed.), National Nuclear Energy Series, Vol. IV-14A, p 347, McGraw-Hi11, New York (1954).

2. A. Brunstad and R. C. Smith. Reduction and Stabilization of Plutonium Nitrate in Cation Exchange Feed and Product Solutions. USAEC Report HW-52796, General Electric Co., Hanford Atomic Products Operation, Richland, Wash. (1957).

3. D. A. Orth. "Plutonium Metal from the Trifluoride." Ind. Eng. Chem. Process Des. Develop. 2, 121 (1963).

4. N. H. Furman and W. W. Scott. Standard Methods of Chemical Analysis. 5 ed., Vol. I, p 647, D. Van Nostrand, New York (1939).

5. J. W. Mellor. Comprehensive Treatise on Inorganio and Theoretical Chemistry. Vol. VIII, Supplement II, p 130, Wiley, New York (1967).

6. J. W. Mellor. Comprehensive Treatise on Inorganic and Theoretical Chemistry. Voll. III, p 303, Wiley, New York (1967).

7. L. L. Smith. Solvent Extraction Data for Plutorizum. USAI:C Report DP-700, E. I. du Pont de Nemours \& Co., Savannah River Laboratory, Aiken, S. C. (1962).

8. J. W. Codding, W. O. Haas, and F. K. Heumann. Equilibrium Data for Purex Systems. USAEC Report KAPL-602, Knolls Atomic Power Laboratory, Schenectady, N. Y. (1951).

9. J. T. Lowe. "Calculation of the Transient Behavior of Solvent Extraction Processes." Ind. Eng. Chem. Process ires. ievelop. 7, 362 (1968).

$\mathrm{TL}: \mathrm{mp}$ 